\title{
Investigation of Jute and Glass Fibre Reinforced Hybrid Composites Manufactured through Compression Molding Process
}

\author{
Md. Jahangir Alam, Mohammad Washim Dewan, Sojib Kummer Paul and Khurshida Sharmin
}

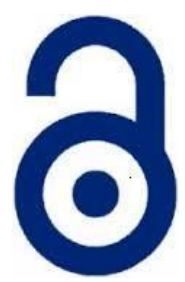

Received: 06 September 2021

Accepted: 05 December 2021

Published: 01 January 2022

Publisher: Deer Hill Publications

(c) 2022 The Author(s)

Creative Commons: CC BY 4.0

\begin{abstract}
Expensive and non-biodegradable synthetic fibres are commonly utilized as reinforcement in composites for better mechanical properties. The eco-friendly and low-cost properties of natural fibres are promising alternative reinforcement for composites. In this study epoxy-based glass and jute fibres reinforced hybrid composites are fabricated varying fibre stacking sequences, 1jute-1glass alternatively (j-g-j-) and 4glass-9jute-4glass (4g-9j-4g). Hybridization of jute and glass fibre results better tensile, flexural and water absorption properties than only jute fibre reinforced composites but inferior to only glass fibre reinforced composites. The $4 \mathrm{~g}-9 \mathrm{j}-4 \mathrm{~g}$ stacking sequence resulted in better mechanical and water absorption properties than j-g-j-- stacking sequence. The effect of chemical treatment and glass microfiber infusion are also investigated. Chemically treated jute fibre and 2 wt.\% microfiber infused hybrid composite shows about $42 \%$ improvements in flexural strength as compared to untreated and without microfiber infused composites. However, fibre chemical treatment and microfiber do not have a positive impact on tensile strength.
\end{abstract}

Keywords: Hybrid Composites; Compression Molding; Chemical Treatment; Micro-filler Infusion; Mechanical Properties.

\section{INTRODUCTION}

Fibre reinforced polymer (FRP) composites have been extensively utilized for many structural applications like automotive parts, airplanes interior parts, household appliances, and construction materials [1]. The environmental concerns have led to substantial attention in the development of new composite materials with addition of more than one reinforcement that is derive from biodegradable resources, such as natural lignocellulosic fibres (i.e., jute, kenaf, hemp, bamboo, wood, etc.) [2]. The adaptation of natural lignocellulosic fibres as reinforcement for different applications has been gaining attention by research communities. According to Science Direct, the number of publications on "Natural Fibre composites" since 1995 has been growing exponentially every year [3]. Natural fibre reinforced composites exhibit lower mechanical properties than synthetic fibre reinforced polymer composites. However, natural fibre reinforced composites properties can be extended by hybridization with synthetic fibres and can provide a sustainable alternative to existing engineering materials in many structural applications. Hybrid fibre reinforced polymers use two or more reinforcements with a single matrix giving rise to a more favourable balance between advantages and disadvantages of two different types of reinforcement $[4,5]$. Hybrid composite materials offer a range of properties that cannot be obtained with a single type of reinforcement. The fibre reinforced polymer composites can be manufactured by adopting various manufacturing techniques such as- hand lay-up, compression molding, injection molding, auto-clave, and vacuum assisted resin transfer molding (VARTM) processes [6].

The combination of a high strength fibre such as glass or carbon with natural fibres can yield a favourable combination of performance, cost and environmental attributes. Glass fibre epoxy composites have been hybridized with jute [7], sisal [8] and bamboo [9] fibres. There are some studies reported on jute fibre reinforced hybrid composites. Ramesh et al. [10] investigated the randomly oriented jute/glass fibre (GF) reinforced polyester composites fabricated with hand lay-up technique. Another research group studied on jute/GF reinforced-epoxy composites with $14 \%$ weight content jute fibres [11]. They utilized hand lay-up and compression molding techniques. Sabeel Ahmed et al. [12] explored the effects of hybridization of glass fibre on low velocity impact behaviour and damage tolerance capability

Md. Jahangir Alam, Mohammad Washim Dewan 凶, Sojib Kummer Paul and Khurshida Sharmin Department of Mechanical Engineering,

Dhaka University of Engineering \& Technology, Gazipur, Bangladesh.

E-mail:washim0179@duet.ac.bd

Reference: Alam et al. (2022). Investigation of Jute and Class Fibre Reinforced Hybrid Composites Manufactured through Compression Molding Process. International Journal of Engineering Materials and Manufacture, 7(1), 35-46. 
of woven jute fabric reinforced composite. The GF content increased the peak load and decreased the energy absorption. The deflection of the specimen was decreased with increasing the GF content.

The hydrophilic natural fibres and hydrophobic polymeric materials when brought together may lead to undesirable mechanical properties due to inadequate interfacial adhesion between them [13]. To improve bonding between natural lignocellulosic fibres and matrix one approach is to treat natural lignocellulosic fibres with some chemicals such as alkali prior using them as reinforcement $[14,15,16]$. In FRP composites the weak properties of matrix and interphase zone is another critical issue that can lead to undesirable characteristics of composites such as interfacial cracking, delamination and decreased fatigue resistance, which in turns severely limits the applications of FRP composites. Infusion of nano / micro-fillers in the FRP that will enhance interfacial bonding by creating bridges between fibre layers that results in improved mechanical properties of the hybrid composite material [17].

There are many researchers around the globe is working on natural fibre reinforced as well as hybrid fibre reinforced composite materials. For the replacement of synthetic fibre reinforced composites with hybrid composites, it requires more research to improve mechanical, thermal and physical properties. As per literature survey, no study reported the effect of fibre stacking sequence, chemical treatment of jute and micro fibre infusion altogether on mechanical and water absorption properties of Jute-glass reinforced hybrid composite. In this study, bi-directional woven jute and glass fibre reinforced hybrid composite panels are fabricated through hand layout followed by compression molding techniques. Different fibre stacking sequences are used for analyzing its effect on mechanical and water absorption properties. Jute fibres are chemically treated and chopped glass microfibers are infused for further improvement of mechanical and water absorption properties.
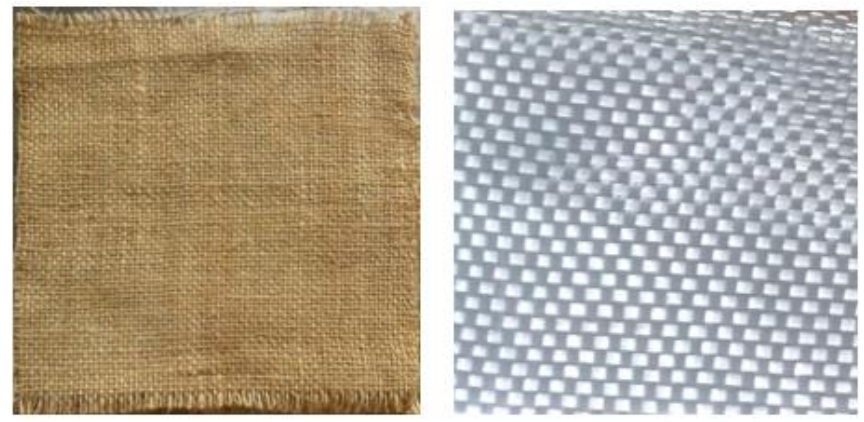

Figure 1: Left) Jute fabric, Right) Glass fabric

\section{EXPERIMENTAL PROCEDURES}

\subsection{Composite Fabrication}

In this research, bi-directional woven mats of jute fibre and glass fibre were used as reinforcement and thermosetting polymer epoxy resin was used as matrix. Curing reaction of epoxy resin took place at room temperature after mixing a curing agent called hardener at a ratio of 10:1. The composites panels were manufactured by hand lay-up followed by a compression molding process. During the fabrication process a releasing agent was first sprayed onto the mold surface. Then a layer of the bidirectional woven fibre was laid down, followed by a quantity of liquid epoxy resin poured onto it. The process was repeated until the required number of layers was built up. Finally, these specimens were taken to the compression molding setup to apply force and remove air gap and excess resin. The panels were cured at pressurized (5000-6000psi) condition at room temperature for 24 hours. Thickness of fabricated were in the range of 5.2-6.5 mm. Figure 2 shows fabricated composite panels ID along with their fibre stacking sequences. Different fibre stacking sequences as well as manually chopped micro glass fibres (20-50 $\mu \mathrm{m}$ length; 2 wt. $\%$ of total fibre weight) were used to observe the variation of mechanical and water absorption properties of the fabricated composite panels. Chopped micro glass fibre first mixed with only epoxy before adding any hardener and stirred manually vigorously to make a proper mixture. To manufacture chemically treated jute fibre and glass reinforced hybrid composite panels, jute fibres were cleaned and immersed into a $5 \% \mathrm{NaOH}$ solution for 2 hours at room temperature $[14,16]$. After that, the jute fibres were filtered and thoroughly washed with distilled water. Finally, the $\mathrm{NaOH}$ treated fibres were dried in an oven at $100^{\circ} \mathrm{C}$ for 2 hours.
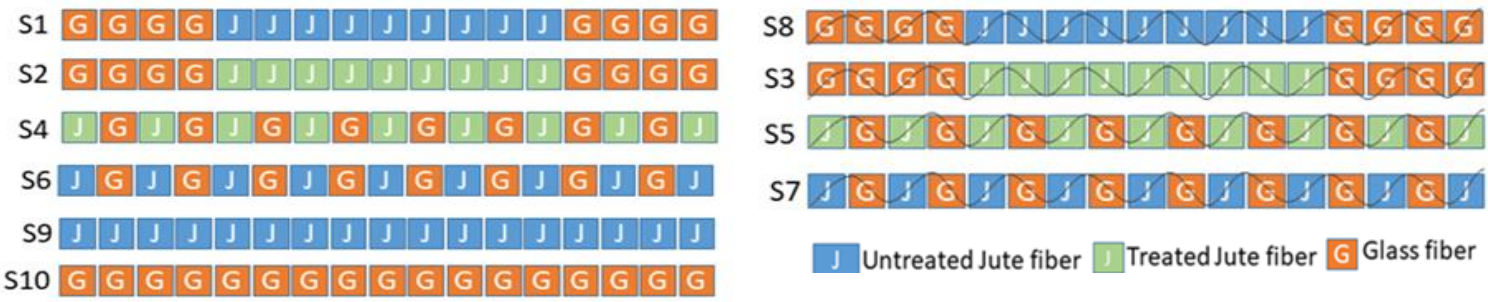

Figure 2: Different fibre sequence and composite ID. Right side composites are with micro filler infused 


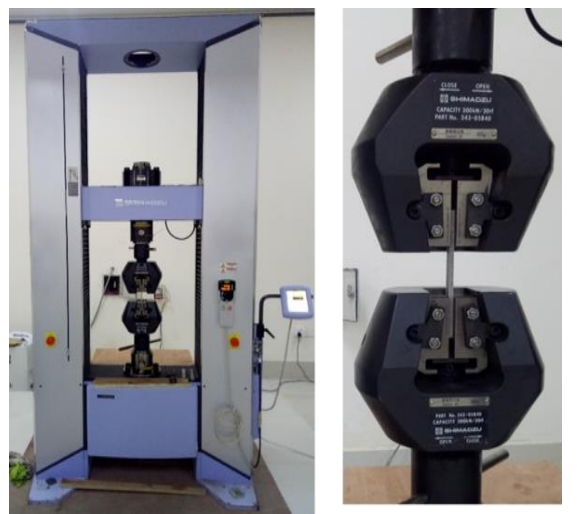

Figure 3: Universal testing machine with tensile testing grip and sample.

\subsection{Tensile Test}

Tensile testing is a destructive test process that provides information about the tensile strength, yield strength, and ductility of the materials. The tensile strength of a composite material is very high in the direction parallel to the fibre orientation, while the tensile strength is much lower if tested in any other direction. The fabricated composites were cut for tensile testing as per the ASTM D3039 standard. Uniaxial tensile test was performed at a cross head speed of $1.2 \mathrm{~mm} / \mathrm{min}$ with Shimadzu 300 knew UTM (Figure 3). At least three samples were tested from each category.

\subsection{Bending Test}

Flexural strength, also known as mod bend strength, or transverse rupture strength is a material property, defined as the stress in a material just before it yields in a flexure test. The transverse bending test is most frequently employed, in which a specimen having either a circular or rectangular cross-section is bent until fracture or yielding using a threepoint flexural test technique. The flexural strength represents the highest stress experienced within the material at its moment of yield. In this work, bending test was carried out by using Shimadzu 300kN Universal Testing Machine at a cross head speed of $2 \mathrm{~mm} / \mathrm{min}$. Support span to depth ratio of 16:1 was maintained. Flexural strength test was conducted as per ASTM D790 standard. Three samples were tested from each category.

\subsection{Interlaminar Shear Strength (ILSS) Test}

The interlaminar shear strength (ILSS) test is used to find out the strength inter laminar shear of multi lamina composite. It is usually determined by the short beam shear (SBS) test. ILSS testing was carried out using a Shimadzu 300 kin Universal Testing Machine under three-point bending mode according to the ASTM D 2344-00 standard at a crosshead speed of $1.3 \mathrm{~mm} / \mathrm{min}$. The span length to depth ratio of the specimen was 6 and the width of the specimen was almost double the thickness. The ILSS was calculated using the eq. (i).

$$
I L S S=(0.75 \times \mathrm{P}) /(\mathrm{b} \times \mathrm{h})
$$

Where, $\mathrm{P}$ is the maximum load $(\mathrm{N}), \mathrm{b}$ and $\mathrm{h}$ are the width and thickness of the specimen, respectively, in $\mathrm{mm}$.

\subsection{Water Absorption Test}

For the water absorption test, the ASTM D5229 standard was followed. Three specimens ( $150 \mathrm{~mm} \times 20 \mathrm{~mm} \times \mathrm{t})$ from each category were dried in an oven at $100^{\circ} \mathrm{C}$ temperature for 1 hour followed by cooling to room temperature in desiccators. Immediately upon cooling the specimens were weighed (i.e. Dry weight, $W 1$ ). The weighted specimens were then immersed into distilled water at room temperature $\left(25^{\circ} \mathrm{C}\right)$ for 24 hours. Immersed specimens were removed, patted dry with a dried cloth paper and weighed (i.e. Wet weight, $W_{2}$ ). Water absorption is expressed as an increase in weight percent (Eq. ii).

$$
\text { Percentages of water absorption }(\%)=\left(W_{2}-W_{1}\right) /\left(W_{1} \times 100\right) \%
$$

\subsection{Morphological test}

Morphological characterization of the fractured composite surface was analysed through a Scanning Electron Microscope (SEM). Composite samples are cleaned properly and cut at the fractured region according to the allowable specimen size of SEM finally observed at the SEM at 1-2KV.

\section{RESULTS AND DISCUSSIONS}

\subsection{Fibre Volume Fraction}

The fraction of fibre reinforcement is very important in determining the overall mechanical properties of fibre reinforced composites. A higher fibre volume fraction typically results in better mechanical properties of the composites. The fibre volume fraction can be calculated using a combination of weights, densities and volume of the matrix and fibres. The fibre volume fraction can be calculated utilizing following three equations (Eq. iii-v). The experimented data and calculated fibre volume fraction are shown in Table 1. 
Table 1: Fibre volume fractions of the fabricated composite panels

\begin{tabular}{ccccc}
\hline Sample ID & $\begin{array}{c}\text { Jute fibre mass } \\
\left(m_{J f}\right), \mathrm{gm}\end{array}$ & $\begin{array}{c}\text { Glass Fibre mass } \\
\left(m_{G f}\right), \mathrm{gm}\end{array}$ & $\begin{array}{c}\text { Matrix mass }\left(m_{m}\right), \\
\mathrm{gm}\end{array}$ & $\begin{array}{c}\text { Fibre volume } \\
\text { fraction }\left(V_{f}\right)\end{array}$ \\
\hline S1 & 99.85 & 155.30 & 121.65 & 0.61 \\
S2 & 117.68 & 165.15 & 121.31 & 0.64 \\
S3 & 90.05 & 181.96 & 125.02 & 0.61 \\
S4 & 110.54 & 181.06 & 108.54 & 0.66 \\
S5 & 96.63 & 170.55 & 133.14 & 0.60 \\
S6 & 89.00 & 198.40 & 98.44 & 0.67 \\
S7 & 95.33 & 200.21 & 133.32 & 0.61 \\
S8 & 91.04 & 195.88 & 109.51 & 0.65 \\
S9 & 216.00 & 0.00 & 300.50 & 0.44 \\
S10 & 0.00 & 482.00 & 150.35 & 0.63 \\
\hline
\end{tabular}

Only jute fibre reinforced composite panels had the lowest fibre volume fraction which is about $44 \%$ and the fibre volume fraction of hybrid composite having different fibre stacking sequences varies between $60 \%-67 \%$. Even though same number of glass and jute fibre lamina were used for composites $\$ 1$ to $\$ 8$ but the total weights of glass and jute fibres were not exactly the same. This is because each fibre lamina's cutting dimension was meant to be $200 \mathrm{~mm}$ by $200 \mathrm{~mm}$, but the actual dimensions varied somewhat when we manually cut them.

Were,

$$
\begin{aligned}
& V_{f}=\frac{v_{f}}{v_{c}} \times 100 \% \\
& v_{c}=\frac{m_{J f}}{\rho_{J f}}+\frac{m_{G f}}{\rho_{G f}}+\frac{m_{m}}{\rho_{m}} \\
& v_{f}=\frac{m_{J f}}{\rho_{J f}}+\frac{m_{G f}}{\rho_{G f}}
\end{aligned}
$$

$V_{f}=$ Fiber volume fraction.

$v_{f}=$ Volume of fiber.

$v_{c}=$ Volume of composite panel.

$m_{J f}, m_{G f}, m_{m}=$ Mass of jute fiber, glass fiber and matrix in the composite panel, respectively.

$\rho_{J f}, \rho_{G f}, \rho_{m}=$ Density of jute fiber $\left(1.3 \mathrm{~g} / \mathrm{cm}^{3}\right)$, E-glass fiber $\left(2.62 \mathrm{~g} / \mathrm{cm}^{3}\right)$ and matrix $\left(1.4 \mathrm{~g} / \mathrm{cm}^{3}\right)$, respectively.

\subsection{Ultimate Tensile Strength}

For the tensile test, at least three specimens from each panel were tested on the universal testing machine (UTM). Tensile stress-strain curves of the fabricated composite panels are presented in Figure 4. All the curves show a similar pattern. Average ultimate tensile strength (UTS) values with standard deviation are presented with a bar graph shown in Figure 5. Only glass fibre reinforced epoxy composites (S10) showed highest average ultimate tensile strength (UTS) value of $391 \mathrm{MPa}$ whereas only jute fibre (untreated) reinforced composite samples (S9) showed lowest average UTS value of $37 \mathrm{MPa}$. Jute fibre is mostly consisting of cellulose which is inherently weaker than synthetic glass fibres made from silicate glass or phosphate-based glass. As a result, in terms of mechanical properties utilizing simply jute fibre as reinforcement is not worthwhile [21]. The hybridization of jute and glass fibres (S1 to S8) resulted in average UTS values much higher as compared to only jute fibre reinforced composite samples (S9). The higher tensile strength values of the hybrid composite panels illustrate the potentiality of the use of hybrid composite material in different structural applications.

The average UTS values of hybridized composite samples also depend on the fibre stacking sequences, chemical treatment of jute fibre and micro-filler reinforcement (Figure 6). Two different types of fibre stacking sequences (4g$9 j-4 g$ and $g-j-g-j-a l t e r n a t i v e l y)$ were investigated in the current study. The untreated jute fibre reinforced $4 g-9 j-4 g$ stacking sequence hybrid composite samples (S1) showed an average UTS value of $191.55 \mathrm{MPa}$ whereas j-g-j-alternatively stacked sequence samples (S6) resulted in UTS value of $219.82 \mathrm{MPa}$. The chemical treatment of the jute fibre did not improve tensile strength of the hybrid composite samples ( $\$ 2$ and $\$ 4$ ). The micro-filler infusion (i.e., $2 \%$ chopped glass fibre) also had no significant effect on the tensile strength of hybridized composite samples (S3, S5, S7 and S8). Micro-filler infusion in the hybrid composite panels might cause a reduction of the overall fibre volume content in the fabricated composite panels which in turns may affect adversely on the UTS values. On the otherhand, micro-fillers usually enhance the flexural strength of the composite panels by making bridging between laminas. For morphological analysis of the tensile tested samples, scanning electron microscopic (SEM) images are analysed. When tensile load is applied most of the composite failed due to fibre breakage and debonding (Figure 7). Due to the uneven distribution of chopped micro fibre agglomeration is seen in the micrographs which explain the reason behind having low tensile strength when micro fibre is added to the composite. This agglomeration acts as a stress concentration point. 

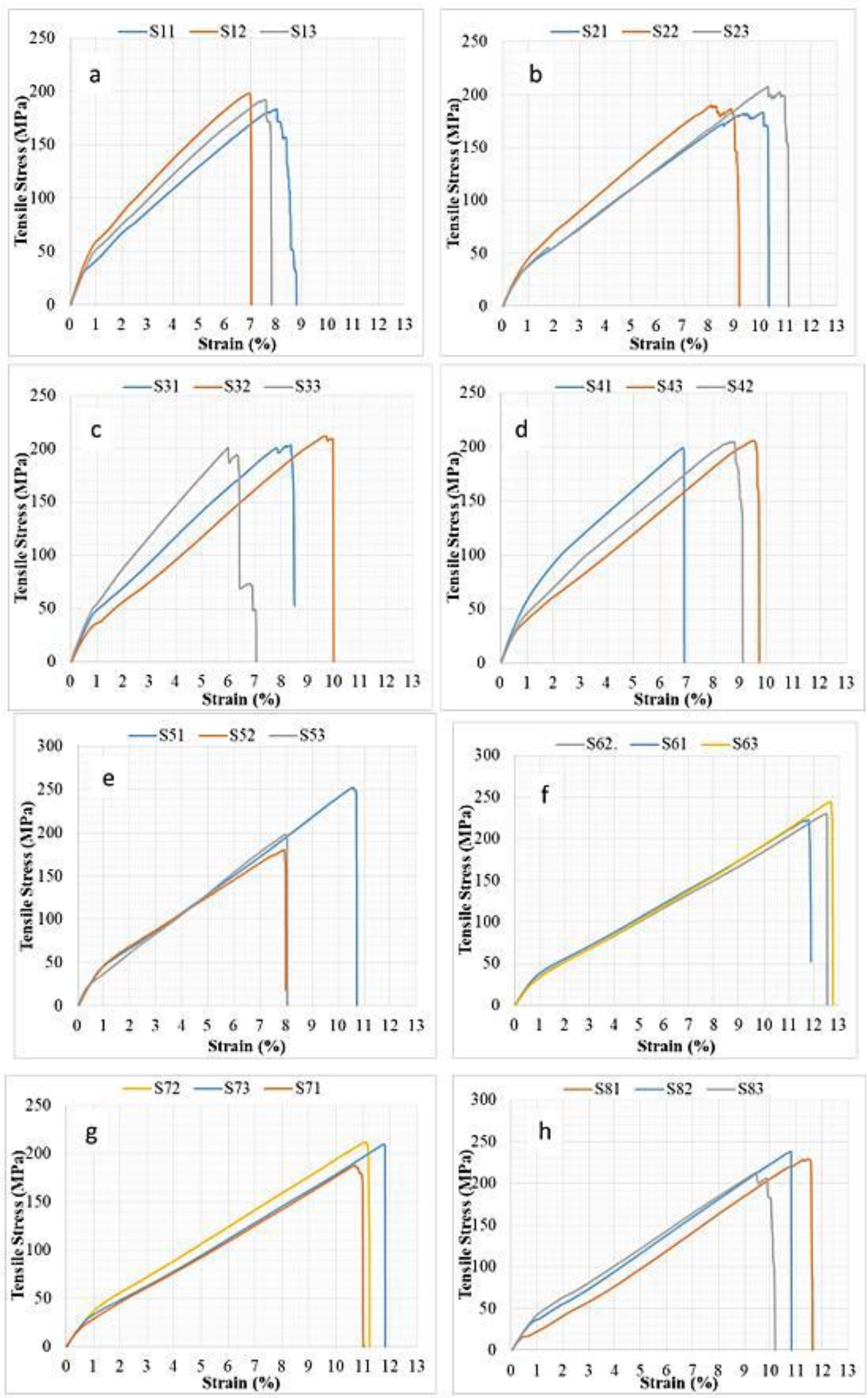

Figure 4: Tensile Stress Strain Curves for Hybrid Composite Panels: (a) S1, (b) S2, (c) S3, (d) S4, (e) S5, (f) S6, (g) 57 and $(h) S 8$ 


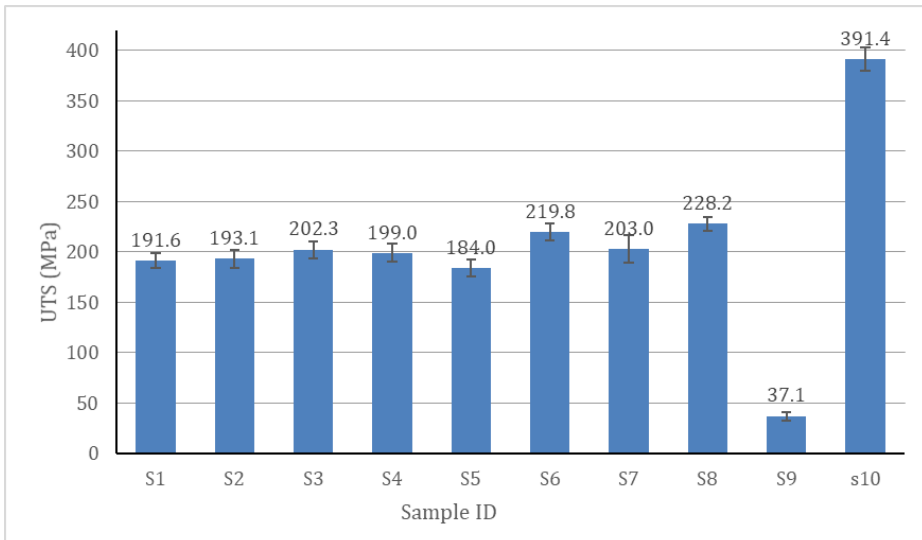

Figure 5: Bar graph showing average UTS values of the different composite panels.

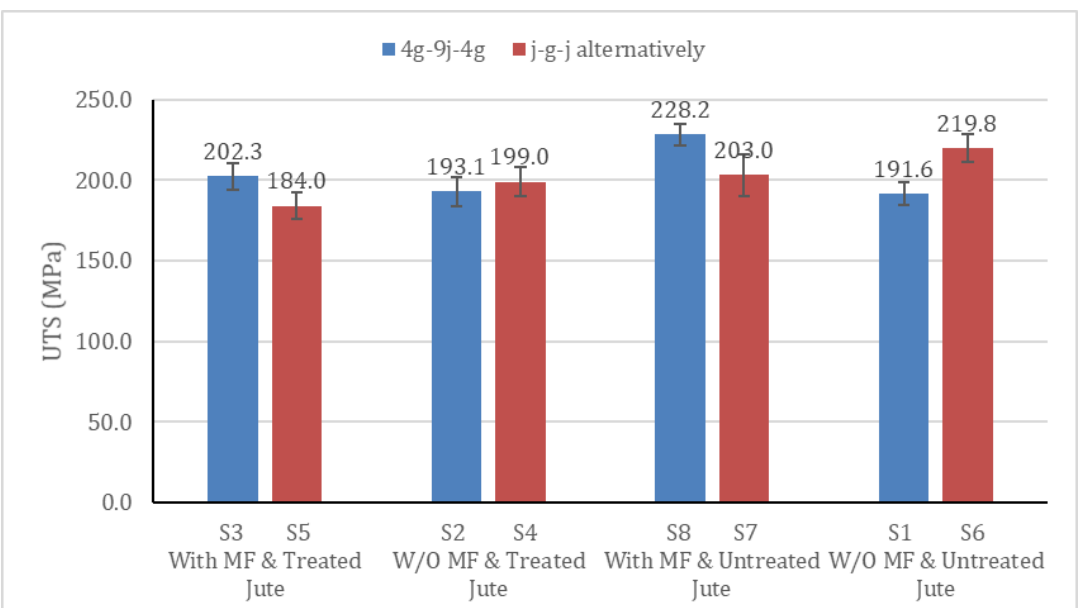

Figure 6: Average tensile strength comparisons of fabricated hybrid composite panels.
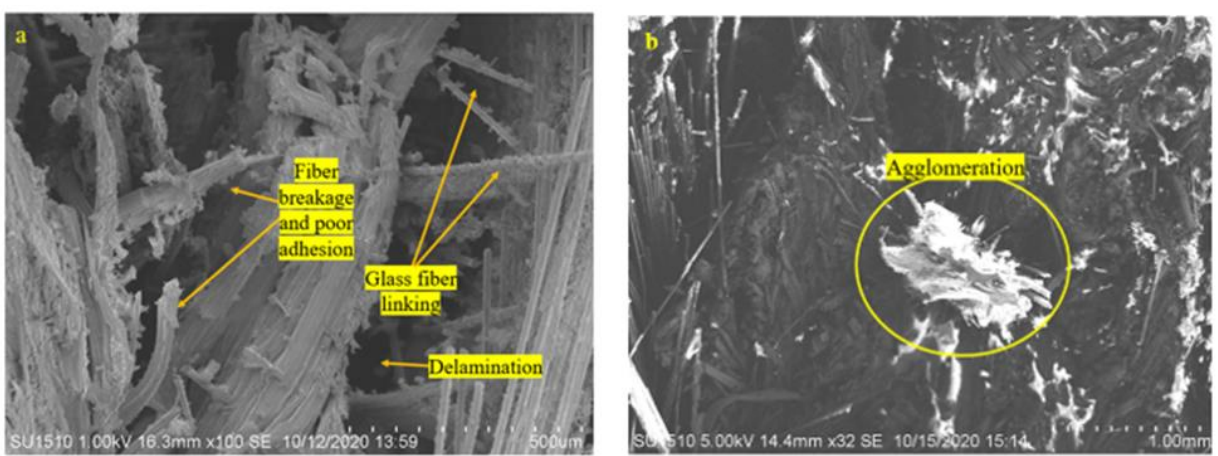

Figure 7: SEM micrographs of fractured tensile samples having 4g-9j-4g stacking sequence with $2 \%$ chopped microfiller: a) Untreated jute and glass (\$8); b) Treated jute and glass (\$3)

\subsection{Bending Strength}

Three-point bending test was performed on fabricated hybrid composite samples. Flexural or bending strengths are calculated from the bending test. Failure due to the three-point bending test mainly occurs due to compression, shear, and tension [18]. Flexural stress-strain curves of the fabricated hybrid composite panels are presented in Figure 8. All the curves show a similar pattern. The average bending strength values are shown in the bar graphs in Figure 9. From the bar graph, it is clearly remarked that the 4g-9j-4g stacked sequence samples (S1, S2, S3 and S8) possess higher bending strength as compared to j-g-j-alternatively stacked sequence samples (\$4, S5, S6, S7). Chemical treatment as well as chopped glass microfiber infusion resulted in higher bending strength of the hybrid composite panels. About $42 \%$ bending strength increased due to chemical treatment of jute fibre and microfiber infusion (S3). The higher bending strength might be related to the higher percentage of cellulose exposure in treated fibres [16] and interlocking action of chopped microfibers $[17,19]$. 
Bending test fractured samples SEM micrographs were also analysed. Almost all composite samples under flexural loading were failed due to fibre breakage and delamination (Figure 10). Figure 10(a) \& Figure 10(b) show micrographs of ruptured bending samples were linking of micro glass fibre is seen. In Figure 10(c) resin adhesion to fibre is visible which indicates the better bonding resulted due to chemical treatment of jute fibre.

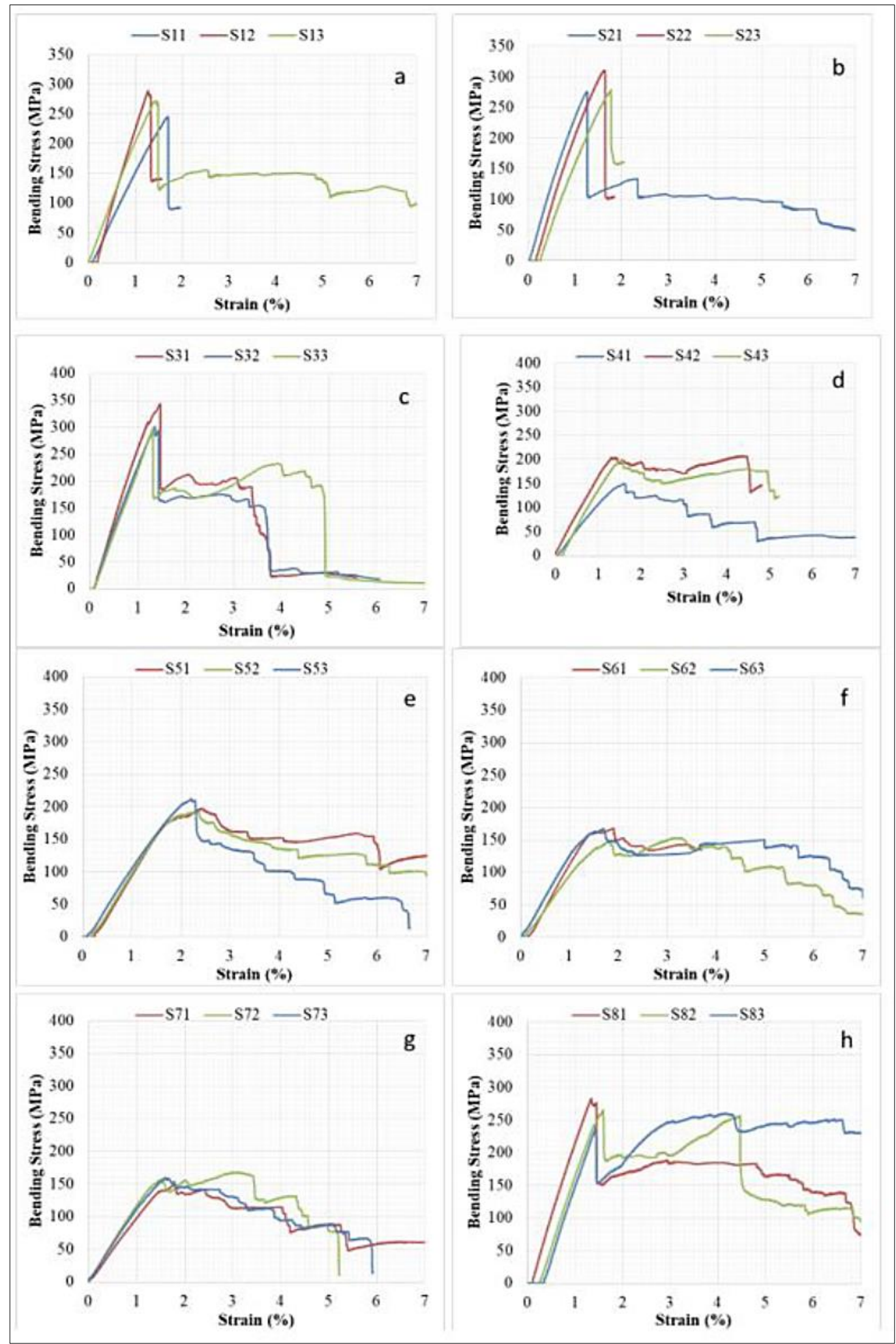

Figure 8: Bending stress strain curves for hybrid composite panels: (a) $\$ 1$, (b) $\$ 2$, (c) $\$ 3$, (d) $\$ 4$, (e) 55 , (f) $\$ 6$, (g) $\$ 7$, and (h) 58 


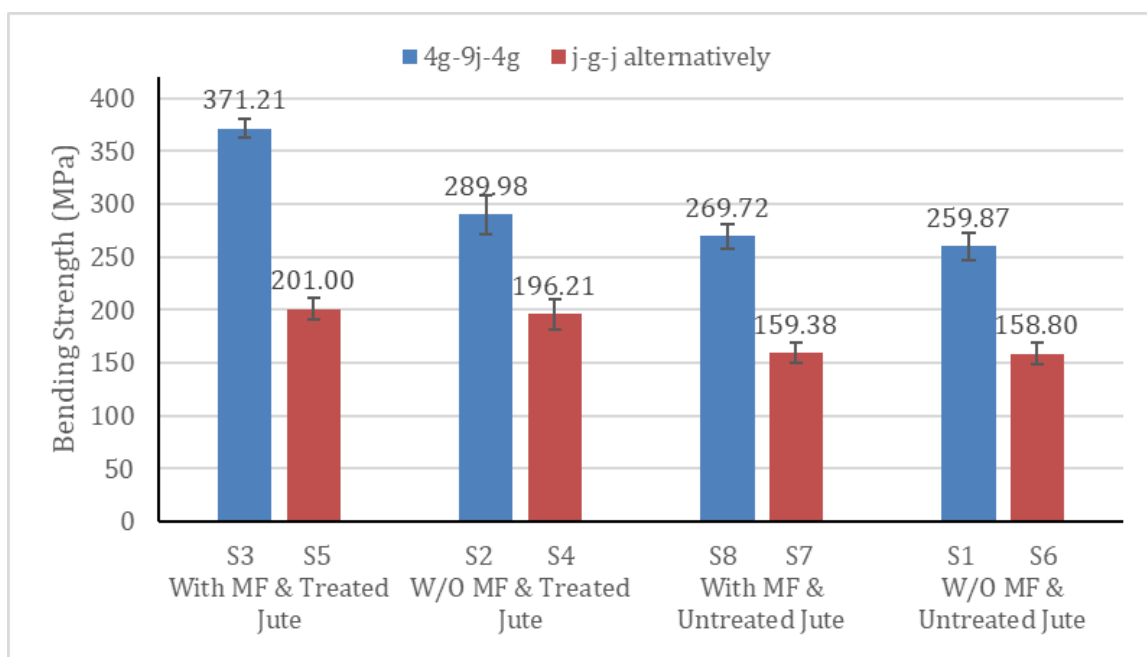

Figure 9: Average bending strength comparisons of fabricated hybrid composite panels.

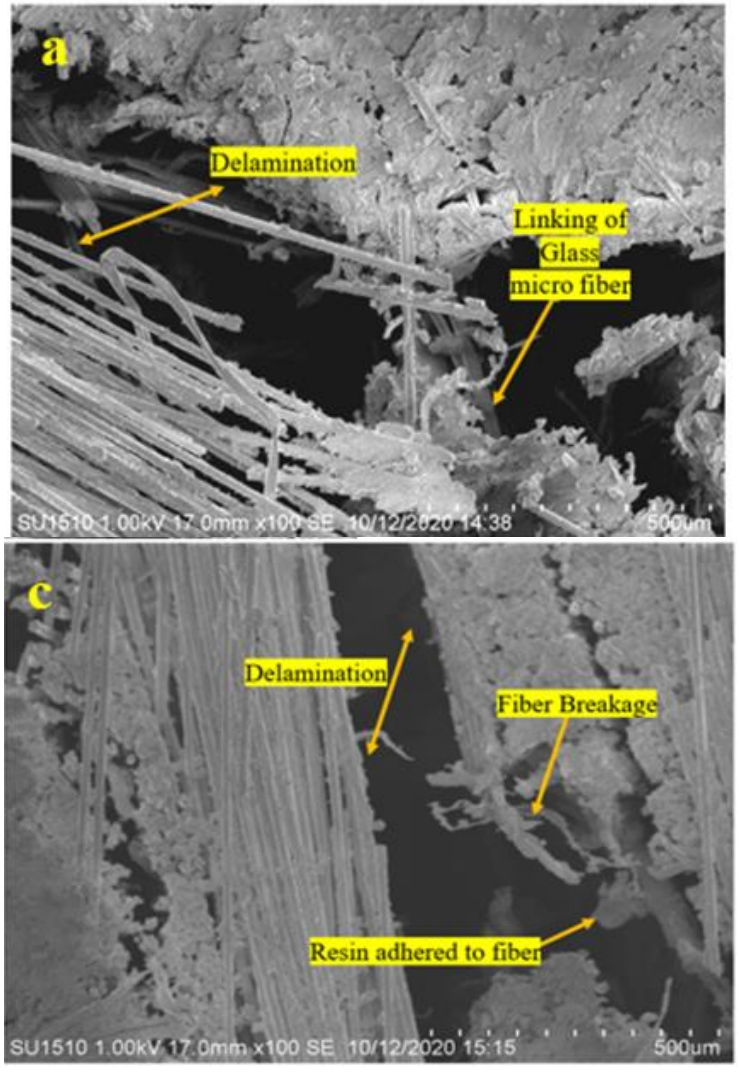

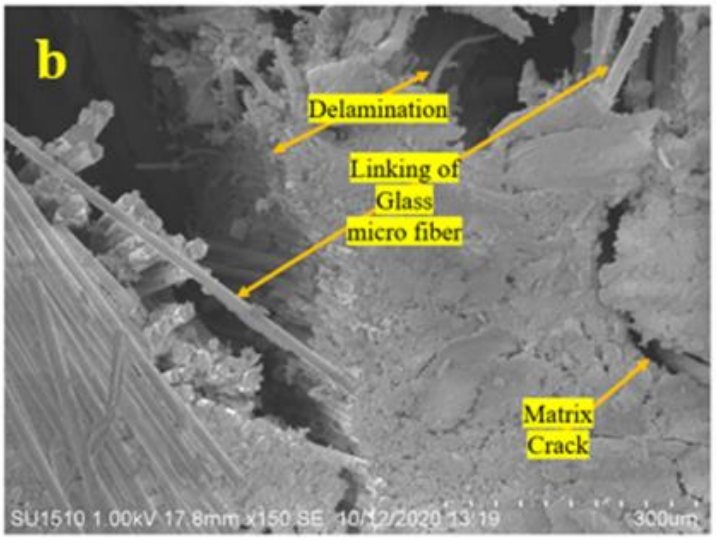

Figure 10: SEM micrographs of fractured bending sample with $2 \%$ chopped micro-filler: a) $4 g-9 j-4 g$ untreated jute and glass (S8); b) $4 \mathrm{~g}-9 \mathrm{j}-4 \mathrm{~g}$ treated jute and glass (S3); c) g-j-g-- alternatively treated jute and glass (S5)

\subsection{Effect of Stacking Sequences on Tensile and Bending Strength}

Tensile strength and bending strength of the fabricated composite panels with 17- layer jute and glass fibres with fibre stacking sequence 4g-9j-4g are shown in Figure 11 and j-g-j-- (alternatively) are shown in Figure 12. It is observed that $4 g-9 j-4 g$ stacked composites lead to improved bending strength than tensile strength while j-g-j-- (alternatively) stacked composites do not have any significant difference. In the 4g-9j-4gstacking sequence composites, the top four and bottom four glass fibres act as a shield to the core jute fibres and bear most of the applied flexural load hence the superior bending strength was observed (Figure 13). However, under tensile strain, the entire core of weak and brittle jute layers cracked simultaneously, leaving the outer glass layers delaminated [21]. This explains the reason for having lower tensile strength than bending in $4 \mathrm{~g}-9 \mathrm{j}-4 \mathrm{~g}$ stacking sequence composites. This result is consistent with other researchers [20]. The chemical treatment of jute fibre and chopped microfiber infusion do not have a significant effect on tensile strength of the fabricated composite panels. However, both chemical treatment of jute fibre and microfiber infusion has a significant effect on bending strength of fabricated hybrid composite panels. 


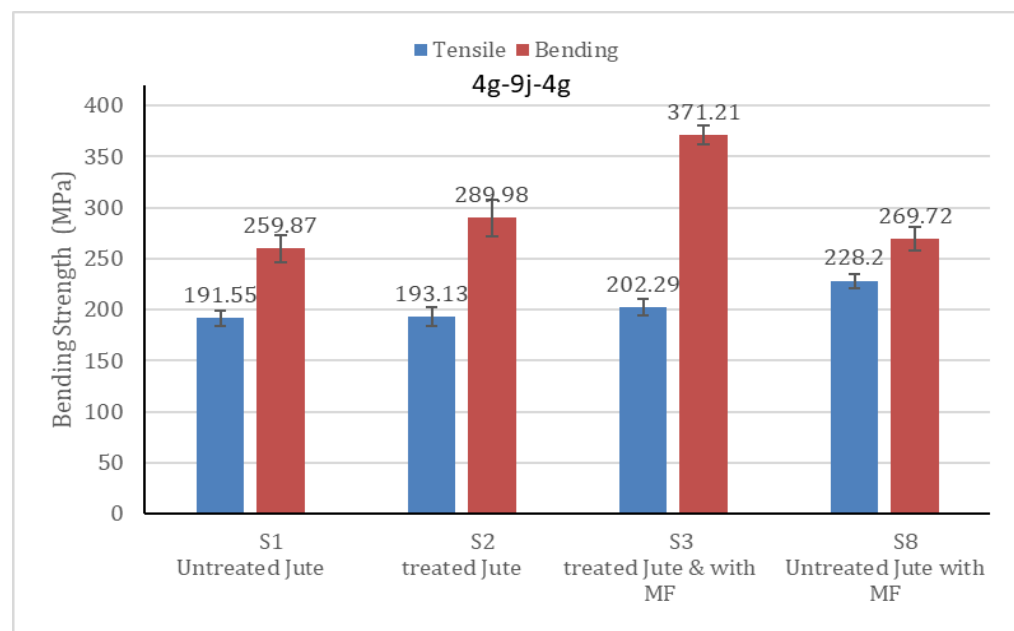

Figure 11: Average tensile and bending strength comparisons of fabricated hybrid composite panels having $4 \mathrm{~g}-9 \mathrm{j}-4 \mathrm{~g}$ stacking sequence.

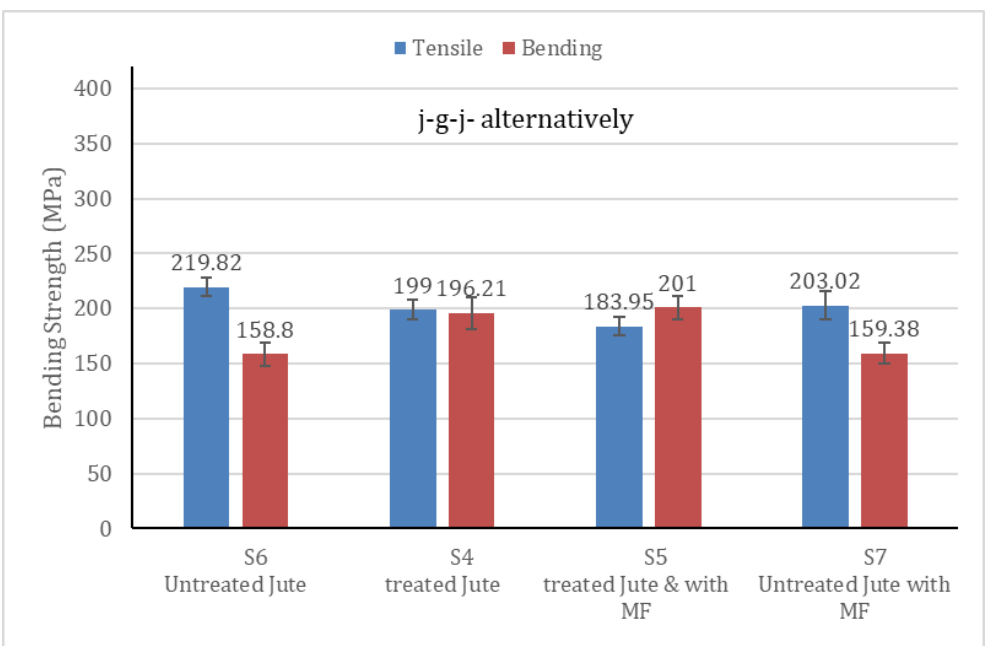

Figure 12: Average tensile and bending strength comparisons of fabricated hybrid composite panels having g-j-g-j-(one by one) stacking sequence.

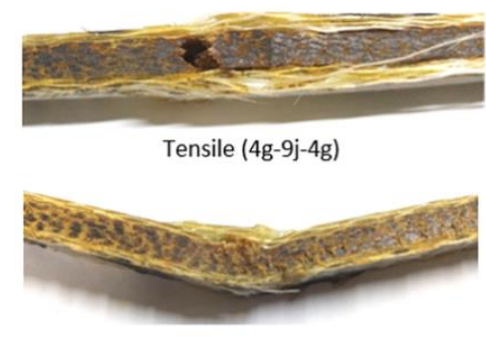

Bending (4g-9j-4g)

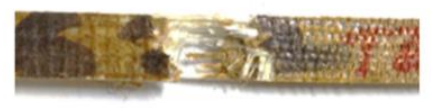

Tensile (j-g-j alternatively)

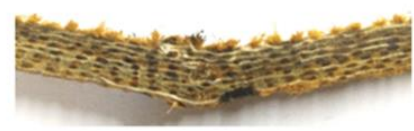

bending (j-g-j alternatively)

Figure 13: Optical images of tensile and bending tests fractured samples having different fibre stacking sequences.

\subsection{Inter Laminar Shear Strength (ILSS)}

Interlaminar shear strength test results of CM composites are Figure 14. ILSS properties of CM composite panels show a similar pattern just as like as flexural properties of CM composite panels. From the bar graph, it is clearly remarked that the $4 \mathrm{~g}-9 \mathrm{j}-4 \mathrm{~g}$ stacked sequence composite panels (S1, S2, S3, and S8) possess higher ILSS as compared to g-j-g-jalternatively stacked sequence composite samples (\$4, S5, S6, S7). Chemical treatments, as well as chopped glass microfiber infusion, resulted in higher ILSS of the hybrid composite panels for enhancing interlocking action.

\subsection{Water Absorption Test Results}

Jute fibres have a high water absorption rate, but glass fibres are less prone to absorb water. Each cell wall of jute fibre is made up of three main components which are cellulose (slender rod like crystalline microfibrils that are 
resistant to hydrolysis), hemicelluloses (hydrophilic polysaccharides that act as a cementing matrix between cellulose microfibrils and can be easily hydrolyzed by dilute acids and bases) and lignin (complex hydrocarbon polymer that assists on the transportation of water). Hydrophilic properties of jute fibres and other natural fibres are attributed to the presence of these hydroxyl and other polar groups [22]. Due to this hydrophilicity sample $\$ 9$ (only jute) composites absorbs maximum water $(2.73 \%)$ than any other hybrid combination of jute and glass fibre. Whereas only glass fibre reinforced composite sample (S10) absorbs lowest amount water (0.63\%) (Figure 15) Hybrid composite panels absorb around $1.5 \%$ water. There is a slight decrement in water absorption observed in chemically treated jute fibre reinforced and chopped glass microfiber infused hybrid composite panels. Water is absorbed due to the capillary action of fibres through micro cracks $[23,16]$. Microcracks were more prevalent in untreated fibre reinforced composites. Treated fibre reinforced and chopped micro fibre infused samples had lower microcracks, resulting in lower water absorption. Chemical treatment also reduces the amount of hydrophilic hemicelluloses from the jute fibre and washes away lignin content which limits water transportation inside composite. These two factors contributed to the lower water uptake in chemically treated fibre reinforced composite. Moreover, infused chopped glass microfiber provided additional resistance to water uptake. As a result, among the hybrid composites panels, sample $\$ 3$ (4g-9j-4g stacking sequence treated and micro-filler infused) has the lowest water absorption capacity which is about $1.48 \%$.

The comparison in water absorption capability of $4 g-9 j-4 g$ and j-g-j-- alternatively stacking sequences in fabricated hybrid composite panels are shown in Figure 16. Samples having 4g-4j-4g stacking sequence have lower water absorption as compared to j-g-j-- alternatively stacking sequence. Stacked hydrophobic glass fibre at the top and bottom in $4 \mathrm{~g}-9 \mathrm{j}-4 \mathrm{~g}$ composites significantly reduce water absorption by acting as a barrier to prevent water from being absorbed by inner hydrophilic jute fibre that gives $4 g-9 j-4 g$ stacking sequence composites the water resistance superiority. Similar results are obtained by another research group for different fibre reinforced composite [20].

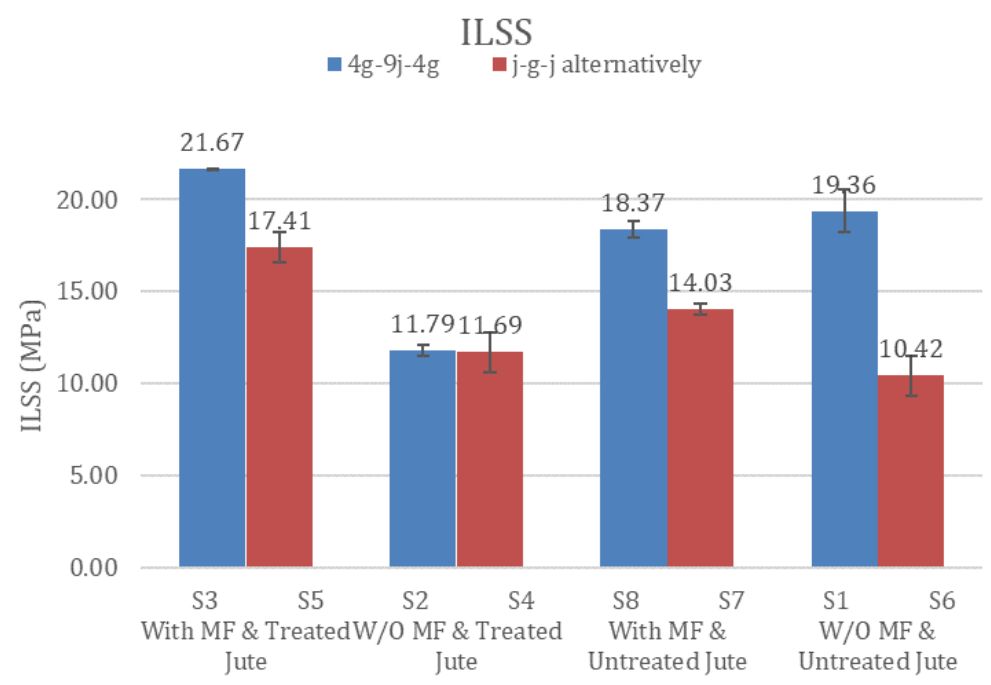

Figure 14: Inter laminar shear strength (ILSS) of hybrid composite panels

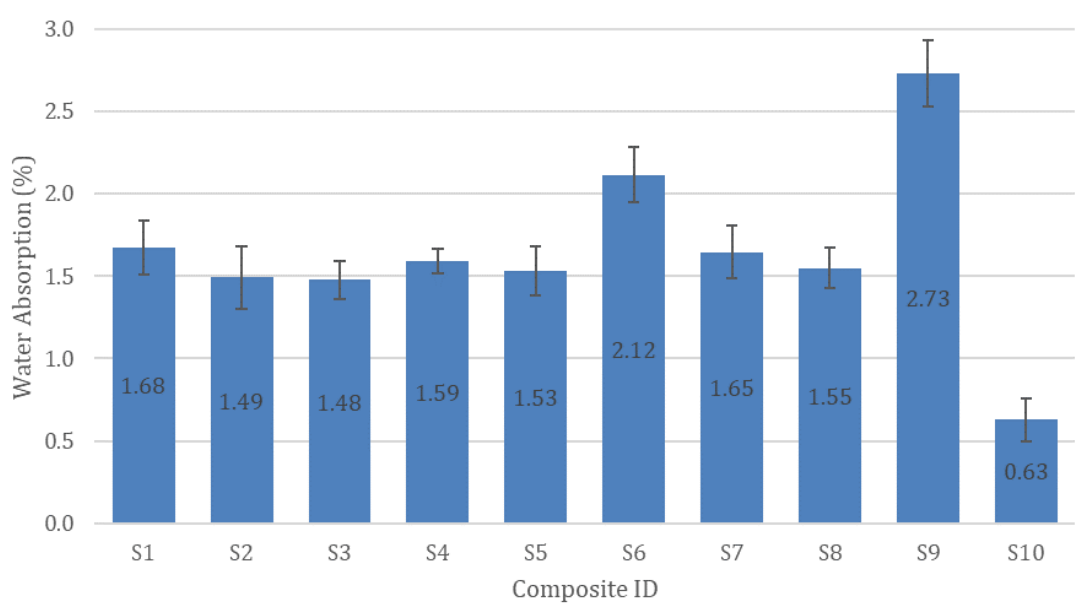

Figure 15: Average water absorption of fabricated composite panels. 


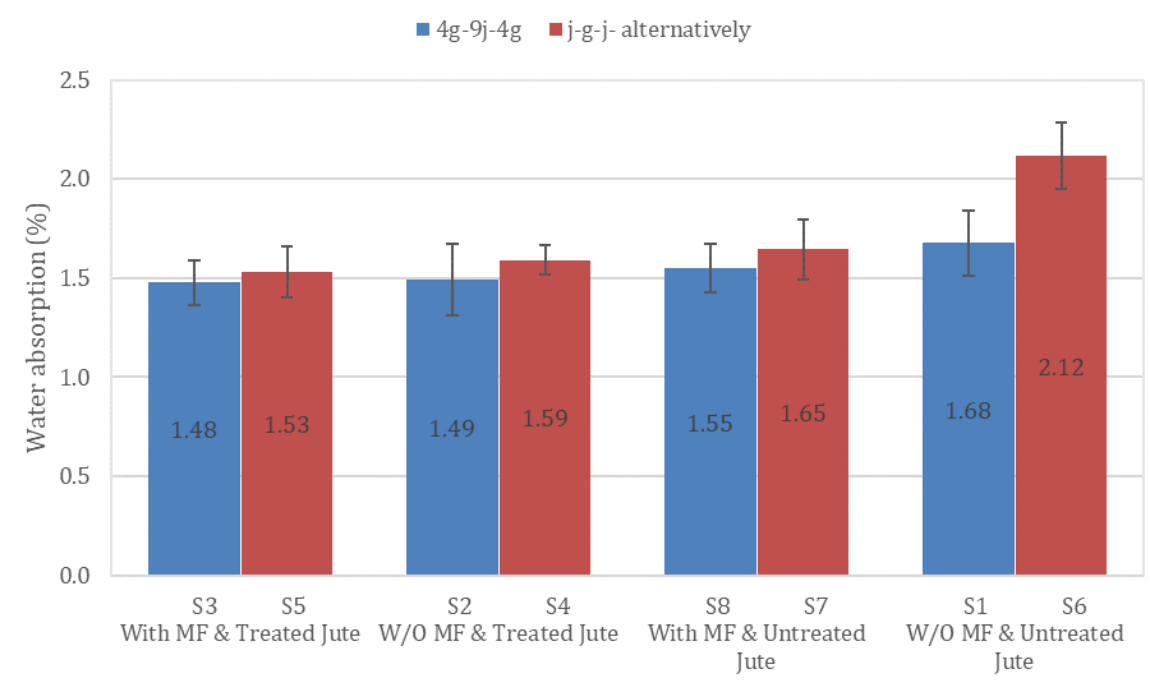

Figure 16: Effect of stacking sequence on water absorption of fabricated composite panels.

\section{CONCLUSIONS}

This work is based on fabrications of hybrid composites with different combination of natural fibre (i. e. jute fibre) and synthetic fibre (i.e. E-glass fibre) as a reinforcement and epoxy resin as matrix utilizing compression molding method. The fabricated composite panels were analysed by comparing different mechanical and physical properties.

1. Only glass fibre reinforced composite resulted in better tensile, bending and water absorption properties compared to other panels which is obvious. Then again only jute fibre reinforced composite panels have lowest tensile and flexural properties and highest water absorption as compared to other fabricated samples. Hybridization of jute and glass fibre resulted in tensile, flexural and waters absorption properties in between only natural and only synthetic fibre reinforced composites.

2. The variations of tensile strength, bending strength and water absorption was observed due to variation of fibre stacking sequences (i.e., positions of lamina). The $4 g-9 j-4 g$ stacking sequences resulted in better mechanical properties as compared to the j-g-j--- (alternatively) stacking sequence.

3. The effect of chemical treatment of jute fibre and infusion of chopped glass microfiber are also investigated in this study. Both the chemical treatment of jute fibre and infusion of microfiber resulted in higher bending strength in the fabricated hybrid composite panels. But the chemical treatment of fibre and microfiber infusion does have insignificant effect on tensile strength and water absorption properties of hybrid composite panels.

4. The fabricated composite hybrid composite panels can be utilized as a replacement of conventional materials in different structural applications.

\section{ACKNOWLEDGEMENT}

The author gratefully acknowledges the funding received from University Grant Commission (UGC) and DUET, Gazipur. Bangladesh. The author would also like to acknowledge the Department of Mechanical Engineering, DUET, Gazipur for permitting to use their testing facilities.

\section{REFERENCES}

1. Sanjay MR, Madhu P, Jawaid M, Senthamaraikannan P, Senthil S, Pradeep S. Characterization, and properties of natural fibre polymer composites: A comprehensive review. Journal of Cleaner Production. 2018;172;566-81.

2. Shahzad A. Hemp fibre and its composites - a review. Journal of Composite Materials.2012;46(8);973-86.

3. Costa U, Nascimento L, Garcia J, Bezerra W, da CostaG, daLuzF.. Mechanical properties of composites with graphene oxide functionalization of either epoxy matrix or curaua fibre reinforcement. Journal of Materials Research and Technology. 2020. 9(6);13390-401.

4. Jawaid M, Abdul Khalil HPS. Cellulosic/synthetic fibre reinforced polymer hybrid composites: A review. Carbohydrate Polymers. 2011;86(1);1-18.

5. Dhakal HN, Zhang ZY, Guthrie R, MacMullen J, Bennett N. Development of flax/carbon fibre hybrid composites for enhanced properties. Carbohydrate Polymers.2013;96(1);1-8.

6. Sathish K. T, Naveen J, Satheesh K. S. Hybrid fibre reinforced polymer composites - a review. Journal of Reinforced Plastics and Composites. 2014;33(5);454-71.

7. Koradiya SB, Patel JP, Parsania PH. The preparation and physicochemical study of glass, jute and hybrid glass-jute bisphenol-c-based epoxy resin composites. Polymer-Plastics Technology and Engineering. 2010; 49(14);1445-49. 
8. Kumar M, Reddy G, Bharathi Y, Naidu S, Naidu V. Frictional coefficient, hardness, impact strength, and chemical resistance of reinforced sisal-glass fibre epoxy hybrid composites. Journal of Composite Material. 2010; 44(26); 3195-202.

9. Kushwaha PK, Kumar R. The studies on performance of epoxy and polyester-based composites reinforced with bamboo and glass fibres. Journal of Reinforced Plastics and Composites. 2010; 29(13);1952-62.

10. Ramesh M, Palanikumar K, Reddy $\mathrm{KH}$. Mechanical property evaluation of sisal-jute-glass fibre reinforced polyester composites. Composites Part B: Engineering. 2013;48;1-9.

11. Ramesh M, Palanikumar K, Reddy KH. Comparative evaluation on properties of hybrid glass fibre- sisal/jute reinforced epoxy composites. Procedia Engineering. 2013; 51; 745-50.

12. Ahmed KS, Vijayarangan S, Kumar A. Low velocity impact damage characterization of woven jute-glass fabric reinforced isothalic polyester hybrid composites. Journal of Cleaner Production. 2007; 26(10); 959-76.

13. Filho F, da Luz F, Oliveira M, Pereira A, Costa U, Monteiro S. Thermal behavior of graphene oxide-coated piassava fibre and their epoxy composites. Journal of Materials Research and Technology. 2020; 9(3); 5343-51.

14. Hossain MK, Dewan MW, Hosur M, Jeelani S. Mechanical performances of surface modified jute fibre reinforced biopol nanophased green composites. Composites Part B: Engineering. 2011; 42(6); 1701 -7.

15. Hamidon $\mathrm{MH}$, Sultan M, Ariffin A, Shah A. Effects of fibre treatment on mechanical properties of kenaf fibre reinforced composites: a review. Journal of Materials Research and Technology. 2019; 8(3); 3327-37.

16. Dewan MW, Hossain MK, Hosur M, Jeelani S. Thermomechanical properties of alkali treated jutepolyester/nanoclay biocomposites fabricated by VARTM process. Journal of Applied Polymer Science. 2013; 128(6); 4110-23.

17. Hossain MK, Hossain ME, Dewan MW, Hosur M, Jeelani S. Effects of carbon nanofibers (CNFs) on thermal and interlaminar shear responses of E-glass/polyester composites. Composites Part B: Engineering. 2013; 44(1); 313 20.

18. Nurazzi NM, Khalina A, Chandrasekar M, Aisyah HA, Rafiqah SA, llyas RA,Hanafee ZM. Effect of fiber orientation and fiber loading on the mechanical and thermal properties of sugar palm yarn fiber reinforced unsaturated polyester resin composites. Polimery. 2020; 65(02);115-24.

19. Gibson RF, Yau A. Complex moduli of chopped fibre and continuous fibre composites: comparison of measurements with estimated bounds. Journal of Composite Materials. 1980; 14(2); 155-67.

20. Sujon MAS, Habib MA, Abedin MZ. Experimental investigation of the mechanical and water absorption properties on fibre stacking sequence and orientation of jute/carbon epoxy hybrid composites. Journal of Materials Research and Technology. 2020; 9(5); 10970-81.

21. Singh H, Preet Singh JI, Singh S, Dhawan V, Tiwari SK. A Brief Review of Jute Fibre and Its Composites, Materials Today: Proceedings. 2018; 5(14); 28427-28437.

22. Azwa ZN, Yousif BF, Manalo AC, Karunasena W. A review on the degradability of polymeric composites based on natural fibres, Materials \& Design. 2013; 47; 424-442.

23. Dhakal HN, Zhang ZY, Richardson MOW. Effect of water absorption on the mechanical properties of hemp fibre reinforced unsaturated polyester composites, Composites Science and Technology. 2007; 67(7-8); 1674-1683. 